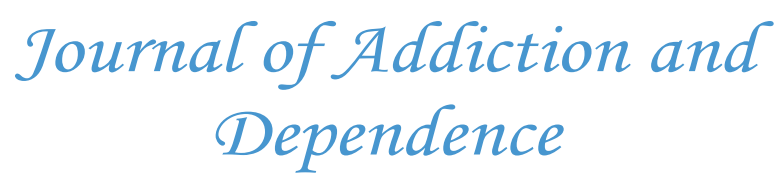

\title{
Comparative Study of Anxiolytic-like Effect of a Novel Herbal Treatment with Diazepam on Balb/c mice
}

\author{
Zouhra Doukkali $^{{ }^{*}}$, Amine Boumahdi ${ }^{2}$, Khalid Taghzouti ${ }^{3}$, El Houcine Bouidida ${ }^{4}$, Rabie Kamal ${ }^{1}$ \\ Mohamed Errami' ${ }^{2}$, Yahya Cherrah ${ }^{1}$, Katim Alaoui ${ }^{1}$ \\ ${ }^{1}$ Pharmacodynamy Research Team, ERP, Laboratory of Pharmacology and Toxicology, Faculty of Medicine and Pharmacy, \\ University Mohammed V of Rabat, Morocco \\ ${ }^{2}$ Faculty of sciences, University Abdelmalek Essaadi - Tetouan \\ ${ }^{3}$ Laboratory of Animal Physiology, Department of Biology - Faculty of Science - University Mohammed V of Rabat, Morocco \\ ${ }^{4}$ National Laboratory of Drug Control, Directorate of Pharmacy, Ministry of Health, Rabat, Morocco
}

*Corresponding author: Zouhra Doukkali, Pharmacodynamy Research Team, ERP, Laboratory of Pharmacology and Toxicology, Faculty of Medicine and Pharmacy, University Mohammed V of Rabat, Morocco.

\begin{abstract}
Background: The most widely prescribed medications for anxiety disorders are the Benzodiazepines; however, they have prominent side effects. Thus, interest in alternative medicine that affects the mind is growing. In Morocco folk medicine, the use of Mercurialis annua is commonly recommended for relief of anxiety, although no scientific information supporting this use is available and therefore we undertook the study to evaluate the anxiolytic potential the methanolic extract of Ma by using a battery of appropriate rodent test models.

Methods: The purpose of this study was to characterize the putative anxiolytic-like effects of methanolic extract prepared from the aerial parts of Ma using the Elevated Plus Maze (EPM) and Open Field tests (OF) in mice. The methanolic extract of Ma was administered orally to Balb/c mice, at graded doses; $1 \mathrm{H}$ prior to behavioural assessments. Results: In the elevated plus-maze test, methanolic extract of Ma at $100 \mathrm{mg} / \mathrm{kg}$ showed an anxiolytic effect by increasing the time spent on and the number of entries into the open arms of the EPM comparable to standard anxiolytic drug, diazepam. In an open field test methanolic extract of $\mathrm{Ma}(100 \mathrm{mg} / \mathrm{kg})$ increased the central area crossing, the time spent and number of rearing in the center of arena.

Conclusions: These observations suggest that Mercurialis annua might possess significant anxiolytic potential.
\end{abstract}

Keywords: Anxiety; Balb/c mice; Elevated plus maze; Open field; Methanolic extract of Mercurialis annua, Morocco.
Received Date: May 9, 2016

Accepted Date: July 9, 2016

Published Date: July 15, 2016

Citation: Doukkali, Z., et al. Comparative Study of Anxiolytic-like Effect of a Novel Herbal Treatment with Diazepam on Balb/c mice. (2016) J Addict Depend 2(2): 84- 90.

DOI: $10.15436 / 2471-061 X-16-022$

Abbreviations: Ma: Mercurialis annua, $\mathrm{MeOH}$ extract: methanolic extract, OF: Open field test, EPM: Elevated plus maze

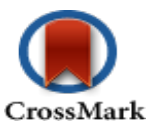

\section{Introduction}

Anxiety disorders are among the most common psychiatric disorders that affect all age groups in the general population. In Morocco, anxiety disorders affect $9 \%$ of the population according to the national survey on mental health conducted by the Ministry of Health ${ }^{[1]}$.

Anxiety disorders include Agoraphobia, Specific Phobia, Social Anxiety Disorder (Social Phobia), Panic Attack, Separation Anxiety Disorder, and Selective Mutism ${ }^{[2]}$ and this trouble became a very important area of research interest in psychopharmacology. It's well known that changes and control of emotion are related to dysregulation and neurochemical abnormalities in a certain specific pathway or neurotransmitter that is theoretically implicated in anxiety.

In a broader view of anxiety, there are at least five neurotransmitters that are "perturbed", namely GABA, nor-adrenaline, serotonin, Corticotropin-Releasing Hormone $(\mathrm{CRH})$, and cholecystokinin ${ }^{[3,4]}$. The interaction between these neurotransmitters is carefully orchestrated in the brain and changes in one neurotransmitter system elicit changes in another. All of these neurotransmitters have become important targets for therapeutic agents either already marketed or in development ${ }^{[5]}$.

Copyrights: (C) 2016 Doukkali, Z. This is an Open access article distributed under the terms of Creative Commons Attribution 4.0 International License. 
Since the introduction of benzodiazepines in the 1960s, they have been the most commonly employed medicinal treatment for anxiety, these classical benzodiazepines act via the benzodiazepine receptors which are present on the GABAA pentameric complex $^{[6,7]}$. Current drug therapies for anxiety are relatively safe drugs for a short-term treatment of anxiety despite their drug dependence potential and side effects ${ }^{[8,9]}$. Therefore, the development of other anxiolytic drugs without such adverse effects is important for the treatment of anxiety disorders and the study of medicinal plants could provide new therapeutic options.

There are numerous plants that have been used for their tranquillizing properties in Morocco traditional medicine.

Mercurialis annua L (Euphorbiaceae) is a wind-pollinated annual plant that occupies ruderal and roadside habitats throughout central and western Europe and around the Mediterranean Basin ${ }^{[10]}$. The species is a winter annual in the Mediterranean region, and has long been known to have tranquillizing effects among the Moroccan people $e^{[11,12]}$.

Reaching $10-50 \mathrm{~cm}$ in height, Ma contains large amounts of flavonoids and of the pyridinone-type alkaloid, hermidin ${ }^{[13]}$. Ethnobotanical reports attribute purgative, diuretic or antisyphilitic effects to the dried plant.

Despite the wide spread use of Ma as an anxiolytic, there are no pharmacological data to support such effect, therefore, we explored the anxiolytic-like effects of Methanolic extract of Ma by using the elevated plus maze and open field tests, classic experimental models.

\section{Materials and Methods}

\section{Animals}

Balb/c mice of either sex (20 - 30 g) were employed in the present study. Animals were procured from the animal experimental center of Mohammed V. University, Medecine and pharmacy Faculty, Rabat. Animals were provided normal diet and water ad libitum and were maintained in a room with controlled temperature of $20-25^{\circ} \mathrm{C}$, and lighting (light/dark 12:12 hour) in polypropylene cages. The animals were acclimatized to the laboratory condition before experiments at least $1 \mathrm{~h}$. The animals were kept fasted $2 \mathrm{~h}$ before drug administration, the Open field and the elevated plus maze were performed between $2 \mathrm{pm}$ and $6 \mathrm{pm}$.

\section{Plant Material}

The aerial part of Mercurialis annua (Ma) was collected from the north of Morocco near the town of Wazzan (Jaaouna el Basra), with assistance of a traditional medical practitioner. The plant was authenticated by botanists of scientific institute Pr. M. Ibn Tatou and Pr. Halim Khammar. A voucher specimen ( $\mathrm{N}^{\circ}$ RAB78984) was deposited in the Herbarium of Botany Department of the Scientific Institute of Rabat.

\section{Preparation of the Methanolic Extract}

The aerial part was dried at room temperature and crushed. $700 \mathrm{~g}$ of plant material was extracted with six litre of methanol by maceration at room temperature $\left(25^{\circ} \mathrm{C}\right)$ over period of 48 hours. Methanol containing the extract was then filtered through Whatman paper and the solvent was vacuum-distilled at $60{ }^{\circ} \mathrm{C}$ in a rotary evaporator. The remaining extract was finally dried by desiccator. Final extract was a dark green paste, with $21.22 \%$ dry weight. The residue was dissolved in water for final suitable concentrations.

\section{Drugs and Chemicals}

The methanolic extract of Ma was suspended in distilled water. Diazepam was diluted with saline to the required concentration before use. It is well known that benzodiazepines act as anxiolytics at low doses and that they induce sedation and muscle relaxant effects at higher doses ${ }^{[14]}$. Therefore, we used diazepam $(1 \mathrm{mg} / \mathrm{kg}$; ip) as a positive control for anxiolytic-like effects.

\section{Treatment Schedule}

Mice were divided into five (5) groups $(n=6)$. Three groups treated orally (p. o.) with graded doses of methanolic extract of Ma $(100,200$ and $400 \mathrm{mg} / \mathrm{kg}$ ). One group received normal saline by the same route to serve as control and remaining group received diazepam (1 mg/kg i.p.). All drugs were freshly prepared before each experiment. The doses of extracts were calculated to administer $0.25 \mathrm{ml}$ of the suspension of extracts to the mice of $20 \mathrm{~g}$. The anxiolytic activity was examined by using the EPM and OF test. The trial was carried out $1 \mathrm{H}$ after the treatments.

\section{Acute Toxicity Study}

The present section of our study has been under taken to study the adverse or hazardous effects of methanolic extract from $\mathrm{Ma}$, accordingly to determine the LD50, to establish the safety of methanolic extract of Ma in Balb/c mice as per OECD guidelines 423.

In acute toxicity studies, single dose of drug given in large quantity to determine immediate toxic effect. Acute toxicity studies are commonly used to determine LD50 of drug or chemicals and natural products.

The procedure was followed as per OECD 423 guidelines $^{[15]}$ (OECD/OCDE. 2002). The extract was administered orally at a dose of $2000 \mathrm{mg} / \mathrm{kg}$ body weight. Mice were kept under observed for 14 days to register possible mortality; their weights were registered and study their behavioral neurological toxicity.

\section{Behavioral Paradigms \\ Elevated plus maze}

The elevated plus maze (EPM) was first proposed as an animal model of anxiety by ${ }^{[16]}$. Was first evaluated for rats ${ }^{[17]}$ and 
later adapted for mice ${ }^{[18]}$. Constructed of black -colored wooden planks consisting of two close arms, $50 \mathrm{~cm} \mathrm{x} 10 \mathrm{~cm} \times 40 \mathrm{~cm}$, and two open arms, $50 \mathrm{~cm}$ x $10 \mathrm{~cm}$, connected to a central platform $(10 \mathrm{~cm} \times 10 \mathrm{~cm})$. Covered with a removable lid, such that the open or closed arms were opposite to each other ${ }^{[17]}$. The maze was elevated to a height of $50 \mathrm{~cm}$ above the floor. During the experiment each mouse was placed in the central compartment facing one of the open arms. The number of entries and the time spent in open arms were recorded for $5 \mathrm{~min}$. An entry was counted when all four paws of the mouse entered an open or closed arm. An increase in open arms entries and increase in time spent in open arms were interpreted as an index of potential anxiolytic activity. The number of closed arm entries was used to assess motor activity ${ }^{[19]}$. All test sessions were taped by using a video camera.

\section{Open field test}

The open field apparatus was an opaque plexiglass cage $(72 \times 72-\mathrm{cm})$ with walls $35-\mathrm{cm}$ in height where the floor was divided with white lines by 16 squares $(18$ X $18-\mathrm{cm})$ of identical dimension. A digital video camera was installed above the cage to record the activity of the mice. The entire room, except the OF was kept dark during the experiment, in this study was evaluated both the general motor activity of the mice to discard hypoactivity, hyperactivity, or no changes associated with treatments, which could interfere with the behavioral activity of the mice in the elevated plus maze also the observed parameters were as follows: (a) total number of crossings, (b) central area crossings, (c) time spent in central area (d) central area rearing ${ }^{[20,21]}$. An animal was placed in the $\mathrm{OF}$ and allowed to freely explore the apparatus for $5 \mathrm{~min}$.

\section{Ethics approval}

The study was conducted in accordance with the accepted principles outlined in the "Guide for the Care and Use of Laboratory Animals" prepared by the National Academy of Sciences and published by the National Institutes of Health and all efforts were made to minimize animal suffering and the number of animals used. Ethics approval was obtained from the central laboratory of animal of Faculty of medicine and pharmacy from the Mohammed V University of Rabat.

\section{Statistical Analysis}

All the results were expressed as mean \pm SEM. All statistical analysis was done using one way Analysis of Variance (ANOVA) followed by the Turkey's post hoc test. $\mathrm{P}<0.05$ was considered as significant when compared to their respective control group.

\section{Results}

\section{Acute Toxicity Study}

Following oral administration methanolic extract of Mercurialis annua at a dose of $2000 \mathrm{mg} / \mathrm{kg}$, P.O., animals were observed for signs of toxicity such as convulsions, hypothermia, hyperactivity, and grooming continuously for $2 \mathrm{~h}$ and for mortality up to $24 \mathrm{~h}$ after administration of the doses. The study of acute oral toxicity showed that oral administration of a single dose of 2000 $\mathrm{mg} / \mathrm{kg}$ of methanol extract of Ma to mice caused no deaths within 14 days the study. No significant changes were observed in body weight and wellness parameters used for evaluation of toxicity

Individual body weights of animals were recorded before the administration of drug on $1^{\text {st }}$ day of the study and thereafter for 14 days of the experiment. Changes in the weight of individual animals were calculated and compared with that of the control animals.

It was noted a change in body weight of treated animals by extract, body weight of these animals underwent a regression in the first days of observation, and after 5 days we noticed that the reweight gradually increased.

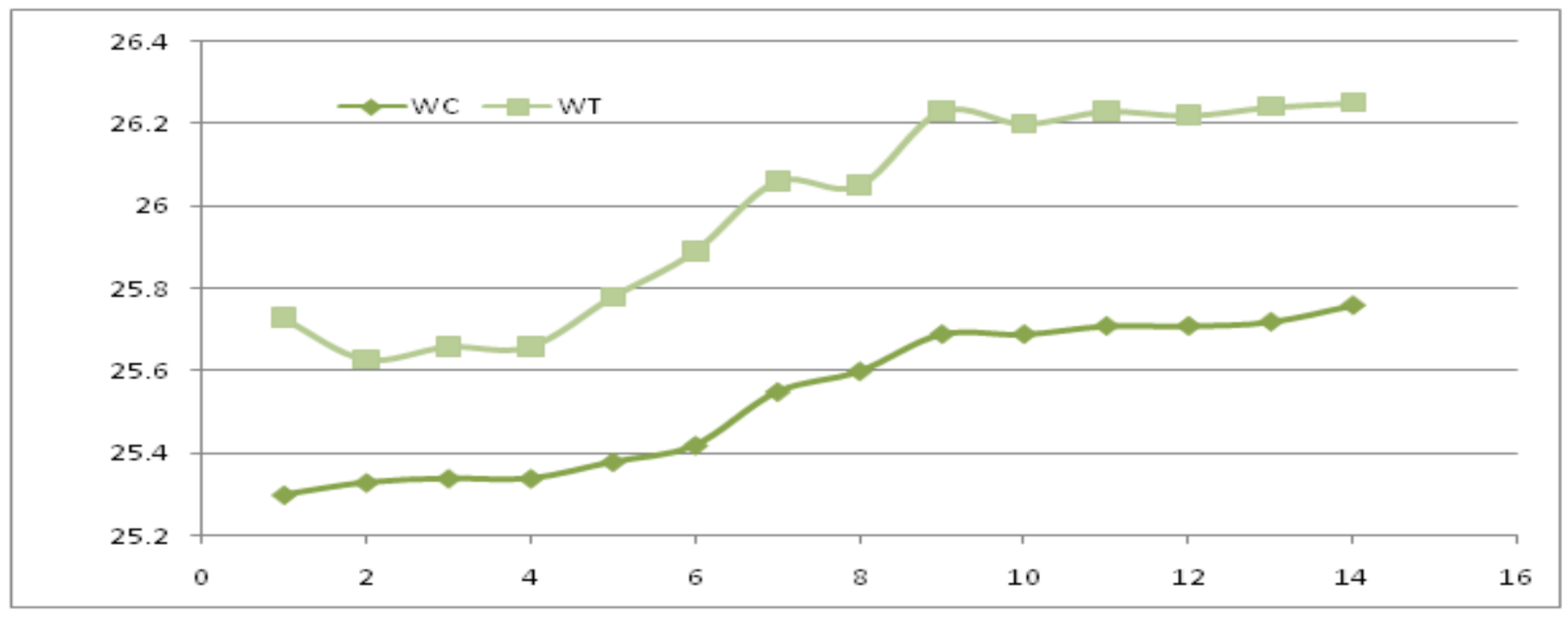

Figure 1: Body weight in control (WC) and treated (WT) within 14 days.

LD50 Value: As per observations and calculations from Acute Oral Toxicity (OECD Guidelines 423), the LD50 value of Methanolic Extract of Ma was found to be more than $2000 \mathrm{mg} / \mathrm{kg}$ body weight. 


\section{Elevated Plus Maze}

One way Anova indicated a significant difference among the groups, mice treated with graded doses of Ma (100, 200, 400 $\mathrm{mg} / \mathrm{kg}$ ) and Diazepam show significant activity when compared to control but group which receive $100 \mathrm{mg} / \mathrm{kg}$ of Ma spent more time on the open arm than other groups.

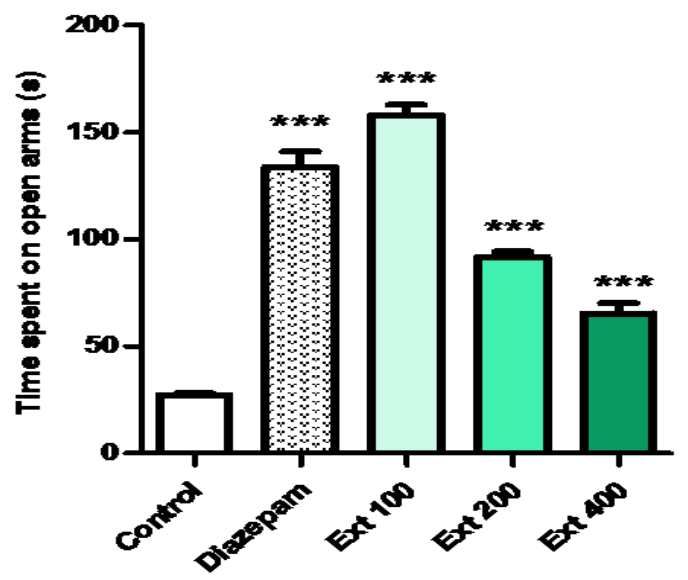

Figure 2: Effect of methanolic extract of Mercurialis annua 100, 200, $400 \mathrm{mg} / \mathrm{kg}$ on time spent on open $\mathrm{arm}(\mathrm{s})$.

The analysis of the number of entries into open arms showed a significant effect among treatments $* * p<0.01, * * * p<$ 0.001 , the post-hoc test showed that the total number of entries into the open arms was augmented $(* * * p<0.001)$ in the group treated with $100 \mathrm{mg} / \mathrm{kg}$ of Ma or $1 \mathrm{mg} / \mathrm{kg}$ of diazepam, when compared with others groups.

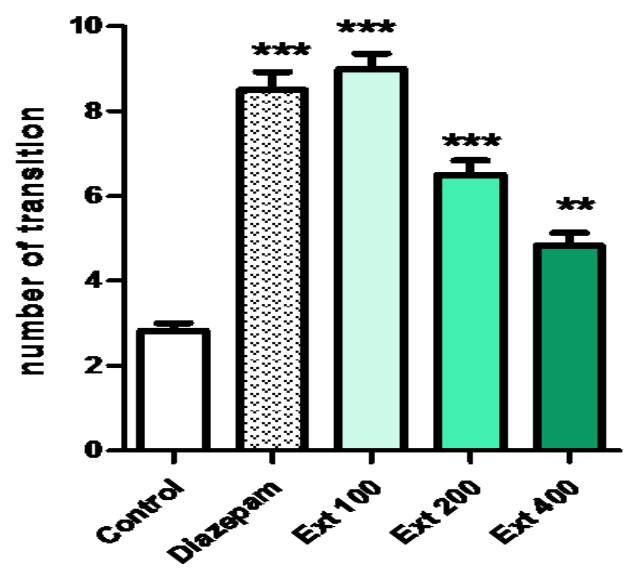

Figure 3: Effect of methanolic extract of Mercurialis annua 100, 200, $400 \mathrm{mg} / \mathrm{kg}$ on number of transition on open $\operatorname{arm}(\mathrm{s})$.

\section{Open Field}

Total crossing:

In the open field test, administration of Ma induced no changes in the total number of crossings. Diazepam showed a slight decrease of locomotor activity but this result is not significant.

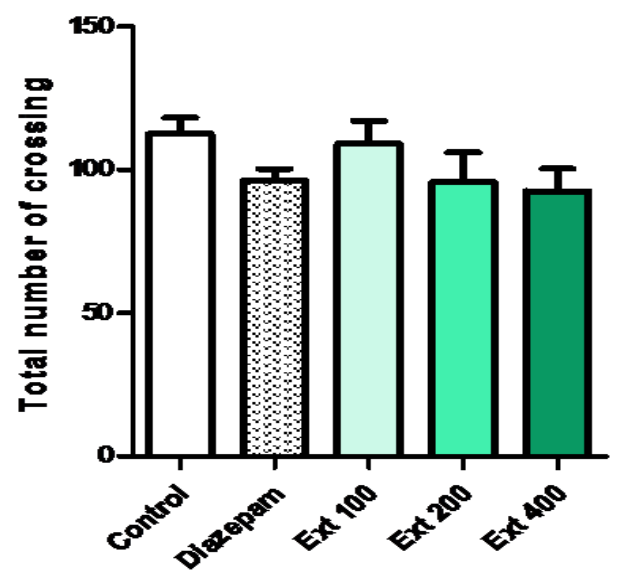

Figure 4: Effect of methanolic extract of Mercurialis annua 100, 200, $400 \mathrm{mg} / \mathrm{kg}$ on Total number of crossing in OF test. 


\section{Central area crossing:}

The number of central area crossings was increased by Ma $(100 \mathrm{mg} / \mathrm{kg})\left({ }^{*} \mathrm{p}<0.05 \mathrm{vs}\right.$. vehicle) and diazepam $(1 \mathrm{mg} / \mathrm{kg})$ $(* * * \mathrm{p}<0.001)$.

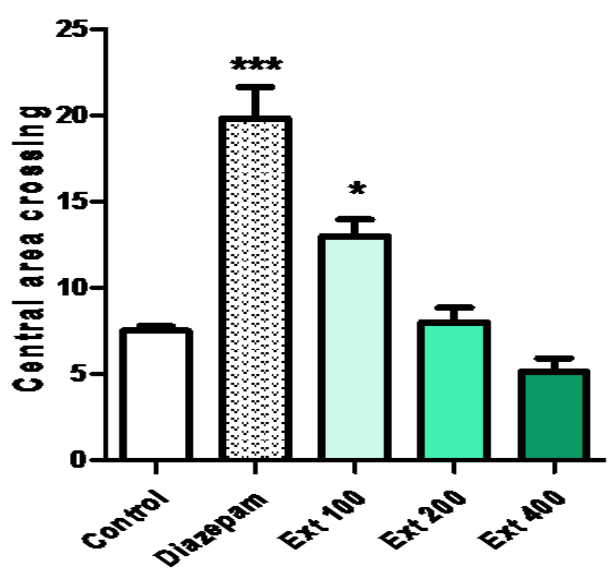

Figure 5: Effect of methanolic extract of Mercurialis annua 100, 200, $400 \mathrm{mg} / \mathrm{kg}$ on central area crossing.

Time spent in central area: $\quad$ Time spent in the central area was increased by Ma $(100 \mathrm{mg} / \mathrm{kg})(* * * \mathrm{p}<0.001 \mathrm{vs}$. control $)$ and diazepam $(1 \mathrm{mg} / \mathrm{kg})\left({ }^{* *} \mathrm{p}<0.01 \mathrm{vs}\right.$. control). The group treated with $100 \mathrm{mg} / \mathrm{kg}$ of methanolic extract of Ma, spent more time in the arena than other groups.

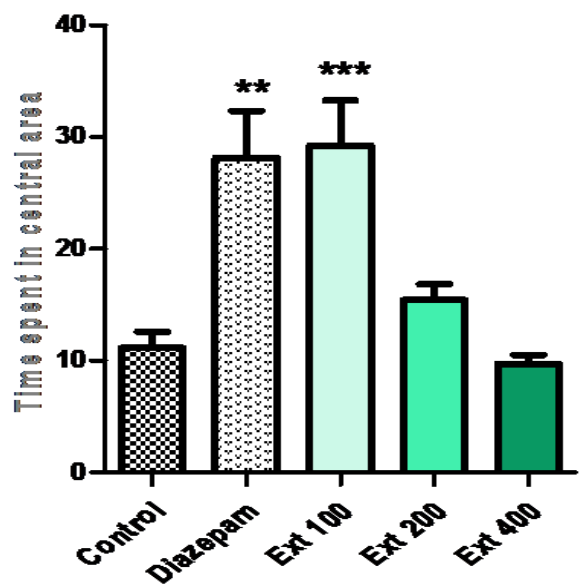

Figure 6: Effect of methanolic extract of Mercurialis annua 100, 200, $400 \mathrm{mg} / \mathrm{kg}$ on time spent on central area.

\section{Central area rearing:}

Rearing behavior in central area was increased by Ma $(100 \mathrm{mg} / \mathrm{kg})(* \mathrm{p}<0.05 \mathrm{vs}$. control $)$ and diazepam $(1 \mathrm{mg} / \mathrm{kg})(* * * \mathrm{p}$ $<0.001$ vs. control).

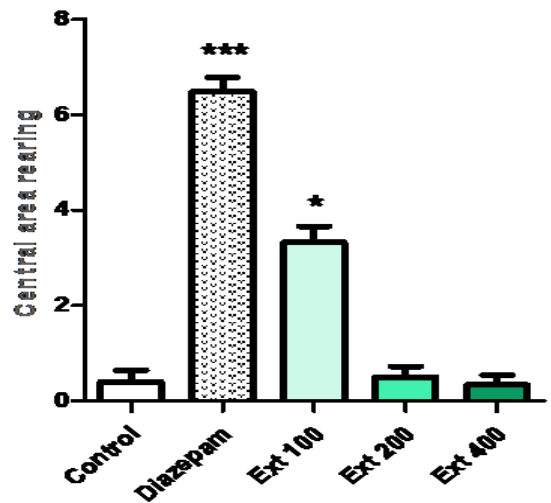

Figure 7: Effect of methanolic extract of Mercurialis annua 100, 200, $400 \mathrm{mg} / \mathrm{kg}$ on central area rearing. 


\section{Discussion}

From the experiment performed as per the OECD Guidelines 423, the results reveal that the methanolic extract of Ma have been found no toxic at $2000 \mathrm{mg} / \mathrm{kg}$ body weight of experimental animals. Skin, fur, eyes, mucous membrane, behavioral pattern, salivation, sleep of the treated as well as the control animals were found to be normal. Insignificant decrease in body weight of test animals indicates that the administration of the extracts does not affect the growth of the animals.

The study analysed the therapeutic potential of Ma extract in experimental models of anxiety in mice. The Ma extract showed promising anxiolytic effects. We have chosen to evaluate the anxiolytic effect in two of the most validated models for researching anxiety like behavior in animals, namely, the EPM and the open field, they are usually the tests of choice when screening for new potential treatment for anxiety disorders.

EPM is based on the natural aversion of rodents for open spaces and uses an elevated plus-maze with two open and two closed arms ${ }^{[22]}$. This test is rapid and was found to be sensitive to the effects of both anxiolytic and anxiogenic agents.

An anxiolytic-like effect appears as decreased open arm avoidance because reduced anxiety removes the interference of fear with exploratory tendencies and hence drives greater exploration of the open arms.

An anxiolytic agent increases the frequency of entries into the open arms and increases the time spent in open arms of the EPM. Diazepam increases the open arm entries and the time spent in the open arms ${ }^{[23]}$, confirming its anxiolytic effects. The aerial part of extract of Ma had similar effects on these parameters.

Animals received $\mathrm{MeOH}$-extract of $\mathrm{Ma}(100-400 \mathrm{mg} / \mathrm{kg}$, po.) and diazepam $1 \mathrm{mg} / \mathrm{kg}$ increased the time spent on the open arms compared to the respective control groups $(\mathrm{P}<0.001$ and $\mathrm{P}<0.001$, respectively).

The values of the group treated with Ma at $100 \mathrm{mg} / \mathrm{kg}$ body weight were higher than that of the treatment with higher doses $(200,400 \mathrm{mg} / \mathrm{kg})$ and diazepam $1 \mathrm{mg} / \mathrm{kg}$.

The number of entries into open arms of the elevated plus maze showing significant $(\mathrm{P}<0.05)$ differences between the groups. Further post hoc comparisons made with Turkey test revealed that animals receiving MeOH-extract of Ma (100 - $400 \mathrm{mg} /$ $\mathrm{kg})$ made statistically significantly more entries into open arms of the maze than control $(\mathrm{P}<0.001$ and $\mathrm{P}<0.01$, respectively) Figure .2. The values of the group treated with $\mathrm{Ma}$ at $100 \mathrm{mg} / \mathrm{kg}$ body weight were higher than that of the treatment with higher doses $(200$, $400 \mathrm{mg} / \mathrm{kg}$ ) and diazepam $1 \mathrm{mg} / \mathrm{kg}$.

A graded dose study of methanolic extract reveals maximum anxiolytic activity of Ma extract at $100 \mathrm{mg} / \mathrm{kg}$, p.o. ( $\mathrm{P}<$ $0.001)$, however the higher dose of $400 \mathrm{mg} / \mathrm{kg}(\mathrm{P}<0.01)$ also showed significant anxiolytic effects at the elevated plus maze model in mice. The anxiolytic effects of the drug saturated at higher doses of $400 \mathrm{mg} / \mathrm{kg}$ as they did not show maximum activity compared with dose at $100 \mathrm{mg} / \mathrm{kg}$.

The OF is capable to induce anxiety in mice and has been widely used to assess the behavioral effects of anxiety ${ }^{[24]}$. The OF allows mice to explore in a novel environment and produces conflicting motivations between fear and exploration with regards to the threatening environment. More thigmotaxis and less locomotion activity is thought to indicate greater anxiety, whereas greater exploration and more ambulation to the centre arena of the OF reflect less emotion ${ }^{[25]}$. The most significant response was observed for the administration of the lower dose of Ma. In the open field test, administration of Ma induced no changes in the total number of crossings which supports the lack of alteration in motor coordination.

Methanolic extract of Ma treatment with $100 \mathrm{mg} / \mathrm{kg}$ body weight increased the preference for the central area enhancing the crossing number, the time spent and the rearing in the central area of the apparatus, an increase in these parameters could be indicative of anxiolytic-like effects ${ }^{[26]}$.

In addition to the fact that this reduction in anxiety like behavior was similar to the one observed following the conventional treatment with the diazepam $1 \mathrm{mg} / \mathrm{kg}$, strengthen the assumption that Ma has anxiolytic affects by its bioactive components and as so can serve as a potential candidate for treating anxiety disorders in humans, perhaps by targeting similar mechanisms as diazepam. A high dose of methanolic extract of Ma produce a sedative effect.

In the present study, Ma extract decreased the level of anxiety in animals. According to this finding, this plant extract is indicated as a significant source of natural antioxidants ${ }^{[27]}$, a new natural flavonol glycoside, isorhamnetin-3-rutinoside-4'-glucoside, together with rutin, narcissin, quercetin-3-(2G-glucosyl)-rutinoside and isorhamnetin-3-rutinoside-7-glucoside, was identified from the $\mathrm{MeOH}$ extract of $\mathrm{Ma}^{[13]}$. We hypothesized that the beneficial effect of this plant might be due to their antioxidant properties, which has the capacity to decrease anxiety, and help to prevent the progression of anxiety.

\section{Conclusions}

In conclusion, the normalcy and insignificant changes in wellness parameters and body weights in the test of toxicity reveals the safety of methanolic extract of Ma at a dose of $2000 \mathrm{mg} / \mathrm{kg}$ body weight.

Our results are promising since Ma might be considered as an alternative for the treatment of anxiety disorders to other medications currently used. Our findings also favor the position that conventional EPM and OF measurements are sufficient and reliable for detecting the anxiolytic effects of Ma extract. The phytoconstituent(s) responsible for the observed central effects has to be isolated and identified in future studies. Future study should be focused on the neurobiological mechanisms of action and possible interactions of Ma extract with classical neurotransmitters and neuromodulators responsible of pathology of anxiety.

Conflicts of Interest: All authors assert that none has any commercial or financial involvements that might present an appearance of a conflict of interest in connection with the submitted manuscript. 


\section{References}

1. Enquête nationale sur la santé psycho-mentale (2004) DELM, M.S.

2. The Diagnostic and Statistical Manual of Mental Disorders. 5th Edition. (2013) American Psychiatric Association.

3. Coplan, J.D., Lydiard, R.B. Brain circuits in panic disorder. (1998) Biol Psychiatry 44(12): 1264-1276.

4. Rush, D., Nickerson, P., Gough, J., et al. Beneficial effects of treatment of early subclinical rejection: a randomized study. (1998) J Am Soc Nephrol 9(11): 2129-2134.

5. The US Surgeon General, Mental Health: A report by the Surgeon General - Chapter 4, Anxiety disorders.

6. Holm, M. Prescription of benzodiazepines in general practice in the county of Arhus, Denmark. (1988) Dan Med Bull 35(5): $495-499$.

7. Rang, et al,. Rang, H., Dale, M., Ritter, J., Gardner, P. Pharmacology. New York, NY: Churchill Livingstone. 1995; $226-229$.

8. Darker, C.D., Sweeney, B.P., Barry, J.M., et al. Psychosocial interventions for benzodiazepine harmful use, abuse or dependence. (2015) Cochrane Database of Systematic Reviews.

9. Malcolm, H.L. Limitations on the use of benzodiazepines in anxiety and insomnia: are they justified?. (1999) European Neuropsychopharmacol 9(6): 399-405.

10. Tutin, T.G., Heywood, V.H., Burges, N.A., et al. Flora Europaea. Cambridge: Cambridge University Press. Durand B. 1963. Le complexe Mercurialis annua L. s.l. une étude biosystématique. Annales des Sciences Naturelles, Botanique, (1964) Paris 12: 579-736.

11. Doukkali, Z., Bouidida, H., Srifi, A., et al. Anxiolytic plants in Morocco: Ethnobotanical and ethno-pharmacological study. (2015) Phytotherapie 13(5): 306-313.

12. Rahenbuhl, M., Yuan, Y.M., Kupfer, P. Chromosome and breeding system evolution of the genus Mercurialis (Euphorbiaceae): implications of ITS molecular phylogeny. (2002) Plant Systematic and Evolution 234: 155-170.

13. Aquino, R., Behar, I., D’Agostino, M., et al. Phytochemical investigation on Mercurialis annua. (1987) Biochem System Ecol 15: 667-669.

14. Novas, M.L., Wolfman, C., Medina, J.H., et al. Proconvulsantand 'anxiogenic' effects of n-butyl $\beta$ carboline-3 carboxylate, an endogenous benzodiazepine binding inhibitor from brain. (1988) Pharmacology Biochemistry Behavior 30(2): 331-336.

15. OECD/OCDE Guidelines for the testing of chemicals, revised draft guidelines 423; acute oral toxicity-acute toxic class method, OECD publishing. (2001).

16. Sharma, V., Gilhotra, R., Dhingra, D., et al. Possible underlying influence of p38MAPK and NF- B in the diminished antianxiety effect of diazepam in stressed mice. (2011) J Pharmacol Sci 116(3): 257-263.

17. Pellow, S., Chopin, P., File, S.E., et al. Validation of open closed arm entries in an elevated plus maze as a measure of anxiety in the rat. (1985) J Neurosci Methods 14(3): 149-167.

18. Lister, R.G. The use of plus-maze to measure anxiety in the mouse. (1987) Psychopharmacology 92(2): 180-185.

19. Sandra, E.F. Factors controlling measures of anxiety and responses to novelty in the mouse. (2001) Behavioural Brain Research $125: 151-157$.

20. Archer, J. Tests for emotionality in rats and mice: a review. (1973) Anim Behav 21(2): 205-235.

21. Siegel, P.S. A simple electronic device for the measurement of gross bodily activity of small animals. (1946) Journal of Psychology 21(2): 227-236.

22. Semba, J., Sakai, M., Miyoshi, R., et al. NG-monomethyl-L-arginine, an inhibitor of nitric oxide synthase, increases extracellular GABA in the striatum of the freely moving rat. (1995) Neuroreport 6(10): 1426-1428.

23. Crawley, J.N., Goodwin, F.K. Preliminary report of a simple animal behaviour for the anxiolytic effects of benzodiazepines. (1980) Pharmacol Biochem Behav 13(2): 167-170.

24. Hall, C.S.. Emotional behavior in the rat. III. The relationship between emotionality and ambulatory activity. (1936) J Comp Psychol 22: $345-$ 352.

25. Choleris, E., Thomas, A.W., Kavaliers, M., et al. A detailed ethological analysis of the mouse open field test: effects of diazepam, chlordiazepoxide and an extremely low frequency pulsed magnetic field. Neurosci Biobehav Rev (2001) 25: 235-260.

26. Prut, L1., Belzung, C. The open field as a paradigm to measure the effects of drugs on anxiety-like behaviors: a review. (2003) Eur J Pharmacol 463(1-3): 3-33.

27. Ljubuncica, P., Azaizehb, H., Portnava, I., et al. Antioxidant activity and cytotoxicity of eight plants used in traditional Arab medicine in Israel. (2005) J Ethnopharmacol 99(1): 43-47.

Ommega Online Publishers

Journal Title: Journal of Addiction and Dependence(JAD)

Journal Short Name: J Addict Depend
ISSN no: 2471-061X

E-mail: addiction.depend@ommegaonline.org Website: www.ommegaonline.org 